\title{
Controle alternativo da podridão peduncular em manga
}

\author{
Severina Rodrigues de Oliveira Lins ${ }^{1}$, Sônia Maria Alves de Oliveira ${ }^{1}$, Elizabeth Rodrigues Alexandre ${ }^{1}$, Alice Maria \\ Gonçalves Santos ${ }^{1} \&$ Thiago Alves Santos de Oliveira ${ }^{1}$
}

\begin{abstract}
${ }^{1}$ Departamento de Agronomia, Área de Fitosanidade, Universidade Federal Rural de Pernambuco, CEP 52171-900, Recife, PE Autor para correspondência: Severina Lins (linsnina@hotmail.com)

Data de chegada: 28/07/2010. Aceito para publicação em: 15/03/2011.
\end{abstract}

1701

\section{RESUMO}

Lins, S.R.O.; Oliveira, S.M.A.; Alexandre, E.R.; Santos, A.M.G.; Oliveira, T.A.S. Controle alternativo da podridão peduncular em manga. Summa Phytopathologica, v.37, n.3, p.121-126, 2011.

O objetivo dessa pesquisa foi verificar o efeito de produtos alternativos em mangas inoculadas com Lasiodiplodia theobromae e a influência desses sobre o crescimento micelial do fitopatógeno. Mangas foram tratadas com fosfato de potássio (FP) (50, 100 e 150), ácido hidroxidobenzóico (AH) (5, 10 e 15), cloreto de cálcio (CC) $(0,13,0,26$ e 0,39$)$ (em milimolar), Luz ultravioleta (LUV) $(10 ; 20$ e 30 min.), extratos de alho (EA), melão-de-são-caetano (EM), casca de manga (ECM) $(25,50$ e $75 \%)$ e água (testemunha). Inoculou-se $10 \mu$ de suspensão de $10^{6}$ conídios $/ \mathrm{mL}$ de $L$. theobromae imediatamente
(T1), 12 horas (T2) e 24 horas, após os tratamentos (T3). No T1, os melhores tratamentos foram FP $(50 \mathrm{mmol})$ e $\mathrm{CC}(0,13 \mathrm{mmol})$. No T2 foram CC $(0,13 \mathrm{mmol}), \mathrm{AH}(5 \mathrm{mmol}), \mathrm{EA}(25 \%)$ e FP $(100$ mmol). No T3 não houve diferença entre os tratamentos. In vitro, os produtos foram misturados ao meio de cultura. Após solidificação, depositaram-se no centro de cada placa, estruturas do fitopatógeno. Quarenta e oito horas após, mediu-se o diâmetro da colônia. Os melhores tratamentos foram FP (100 e $150 \mathrm{mmol})$, ECM $(50$ e $75 \%)$ e EA $(50 \%)$.

Palavras-chave adicionais: Mangifera indica, pós-colheita, manejo, Lasiodiplodia theobromae.

\section{ABSTRACT}

Lins, S.R.O.; Oliveira, S.M.A.; Alexandre, E.R.; Santos, A.M.G.; Oliveira, T.A.S.; Alternative control of stem-end rot in mango. Summa Phytopathologica, v.37, n.3, p.121-126, 2011.

The aim of this study was to evaluate the effect of alternative products in mango sleeves inoculated challenged with Lasiodiplodia theobromae and its influence on the mycelial growth of the pathogen in vitro. Mangoes were treated with: potassium phosphate $(50,100$ and 150), hidroxidobenzóico acid (5,10 and 15), calcium chloride $(0.13,0.26$ and 0.39 ) (in mmol), ultraviolet light ( 10,20 and 30 min.), extracts of garlic, melons of the Caetano, bark of mango (25, 50 and $75 \%$ ) and water (control). The design was a split plot. $10^{6}$ con./mL was inoculated immediately after each treatment (T1), twelve hours after (T2) and twenty-four hours after (T3). In T1, the best treatments were $\mathrm{PO}(50 \mathrm{mmol})$ and $\mathrm{CC}(0.13 \mathrm{mmol})$. T2 in there were CC $(0.13 \mathrm{mmol})$, AH $(5 \mathrm{mmol})$, EA $(25 \%)$ and FP $(100 \mathrm{mmol})$. In $\mathrm{T} 3$ there was no difference between treatments. In vitro treatments were mixed into the culture medium. After solidification it was placed in the center of each plate, structures of the phythopathogen. The model was in DIC with 6 replications. After 48 hours it was measured the diameter of the colony. The best treatments were FP (100 and $150 \mathrm{mmol})$, ECM (50 and 75\%) and EA (50\%).

Keywords: Mangifera indica, postharvest, manegement, Lasiodiplodia theobromae.

A manga (Mangifera indica L.) é uma fruta polposa, de aroma e cor muito agradável, a qual faz parte do elenco das frutas tropicais de importância econômica não só pela aparência exótica, mas também por ser uma rica fonte de carotenóides, minerais e carboidratos (5) e está entre as frutas mais valorizadas para a exportação, alcançando a oitava posição em relação ao volume de comercialização no mundo e a terceira posição no ranking das exportações brasileiras em 2008, atingindo 95.387.206 Kg (16). Do total de frutas produzidas anualmente no Brasil, apenas $1 \%$ é exportada devido às perdas que ocorrem na pré e pós-colheita. Estas perdas correspondem a aproximadamente $30-40 \%$ da produção e ocorrem por vários fatores como danos mecânicos, distúrbios fisiológicos e/ou ocorrência de doenças (6). As perdas ocasionadas por fitopatógenos na fase póscolheita são bastante significativas, pois além das perdas quantitativas, constatam-se ainda as perdas qualitativas, as quais são expressas pelo surgimento de manchas ou outros sintomas de doenças que afetam a parte externa da fruta causando a depreciação da qualidade (11).

A redução das perdas em pós-colheita na cadeia produtiva de manga representa um constante desafio, considerando que as frutas são órgãos que apresentam alto teor de água e nutrientes e, mesmo depois da colheita até a senescência mantém vários processos biológicos em atividade, apresentando desta forma maior predisposição a distúrbios fisiológicos, danos mecânicos e ocorrência de podridões (18).

O aumento dos açúcares solúveis, de água livre e das pectinas, é acompanhado pela redução de alguns componentes fenólicos e protopectínicos, que tornam os frutos mais sensíveis ao ataque de micro-organismos, principalmente de fungos causadores de podridões 
(22). O declínio da resistência natural das frutas pode ativar infecções quiescentes e aumentar a incidência de doenças (28). Dessa forma, o controle das doenças em pós-colheita é uma atividade imprescindível para manter a qualidade e aumentar a vida de prateleira dessa fruta, especialmente quando o período entre a colheita e o consumo for amplo.

Dentre as doenças que ocorre em mangas, a podridão peduncular cujo agente causal é Lasiodiplodia theobromae (Pat.) Riffon \& Maubl., merece atenção. $\mathrm{O}$ fungo penetra pelo pedúnculo e infecta a fruta, permanecendo em quiescência enquanto a fruta não atinge o ponto de amadurecimento, quando provoca a podridão peduncular. Além disso, ocasiona infecções nas partes laterais da polpa, desqualificando a fruta para o mercado $(15,19)$.

$\mathrm{Na}$ perspectiva de reduzir as podridões pós-colheita, várias tecnologias têm sido adotadas além do controle químico, como por exemplo, o controle biológico (antagonistas), o controle físico (refrigeração, tratamento térmico, radiação UV, atmosfera controlada e modificada) e a indução de resistência (elicitores bióticos e abióticos). A eficácia dessas medidas de controle pode variar conforme a espécie ou cultivar, a maturação fisiológica e as características bioquímicas do tecido da fruta (2). Complementando, Nurnberger e Brunner (21) relataram que a utilização de extratos naturais de plantas como prétratamentos para o controle de doenças pós-colheita está baseada na premissa de que estes representam mistura de varias substâncias solúveis capazes de elicitar respostas de defesa em plantas ou agir diretamente sobre o fitopatógeno.

A exploração da atividade biológica de compostos secundários presentes no extrato bruto de plantas também pode se constituir em mais uma forma potencial de controle alternativo de doenças em plantas cultivadas. Grupos de pesquisa de todo o mundo buscam definir o papel de cada substância participante dos processos bioquímicos de defesa das plantas. Dessa forma, o objetivo dessa pesquisa foi verificar o efeito de produtos alternativos bióticos e abióticos, em mangas desafiadas com $L$. theobromae, bem como, verificar a influência desses produtos sobre o crescimento micelial do fitopatógeno, in vitro.

\section{MATERIAL E MÉTODOS}

O experimento foi conduzido no Laboratório de Patologia PósColheita da Universidade Federal Rural de Pernambuco, com mangas sadias da cv. Tommy Atkins, em estádio dois de maturação comercial, obtidas da Fazenda Agrodan, situada no município de Belém do São Francisco, estado de Pernambuco.

Neste estudo foram testados sete produtos: cloreto de cálcio (CC), ácido hidroxidobenzóico (AH), fosfato de potássio (FP), luz ultravioleta (LUV) no comprimento de onda de 270nm, extrato de melão-de-são-caetano (Momordica charantia L.) (EM), extrato de casca de manga (ECM), extrato de alho (Allium sativum L.) (EA), e água destilada esterilizada (ADE) (testemunha), nas dosagens de: CC - 0,13 mmol (D1); 0,26 mmol (D2); 0,39 mmol (D3); AH - $5 \mathrm{mmol}$ (D1); $10 \mathrm{mmol}$ (D2) e $15 \mathrm{mmol}$ (D3); FP - $50 \mathrm{mmol}$ (D1); $100 \mathrm{mmol}$ (D2); e 150 mmol (D3); EM, ECM e EA - 25\% (D1), 50\% (D2), e $75 \%$ (D3) do extrato bruto, respectivamente, e LUV nos tempos de 10 min. (D1), 20 min. (D2) e 30 min. (D3) de exposição das frutas. Estes produtos tiveram seus efeitos avaliados sobre o fitopatógeno em três tempos diferentes. Mangas sadias foram lavadas com água corrente e sabão e secas sobre papel toalha em temperatura ambiente e, em seguida, imersa nos diferentes tratamentos. Cada produto foi diluído em 10 litros de água destilada, exceto para LUV, que constou o tempo de exposição das frutas.

\section{Formulação dos extratos}

Coletaram-se ramos e folhas de melão-de-são-caetano, no Campus da Universidade Federal Rural de Pernambuco. O material foi lavado em água corrente e seco em temperatura ambiente por quatro horas, sobre papel absorvente. Em seguida, foi conduzido à secagem em estufa a $60^{\circ} \mathrm{C}$ por 48 horas e, posteriormente, submetido à trituração, em liquidificador. Assim preparado, o material foi empregado na obtenção do extrato aquoso adicionando-se $80 \mathrm{~g}$ do material em um litro de água destilada, obtendo-se um extrato bruto a $80 \%$, o qual permaneceu em infusão a temperatura ambiente, em local livre de qualquer luminosidade por 72 horas.

Após este período, o extrato foi filtrado em papel filtro e refrigerado por, no máximo, sete dias. Para o extrato de casca de manga, utilizaramse mangas da cv. Tommy Atkins de um pomar particular situado no município de Camaragibe - PE o qual nunca recebeu nenhum tipo de tratamento químico, sendo as frutas consideradas orgânicas. Para a formulação do extrato, selecionaram-se apenas as cascas, previamente lavadas em água corrente e secas a temperatura ambiente $\left( \pm 27^{\circ} \mathrm{C}\right)$, as quais foram mantidas em estufa por 48 horas a $40^{\circ} \mathrm{C}$. Após a secagem, o material foi triturado e elaborado da mesma forma que o extrato anterior. $\mathrm{O}$ extrato de alho foi obtido de bulbos comerciais moídos em multe processador e preparado conforme a metodologia descrita para os demais extratos.

\section{Origem do isolado}

O inóculo constituiu de suspensão de esporos de L. theobromae, obtido de ramo de mangueira com sintomas de morte descendente e cultivados em placas de Petri, contendo Batata-dextrose-ágar (BDA), durante 25 dias. Após este período, foram retirados picnídios das colônias e macerados em $2 \mathrm{~mL}$ de água destilada utilizando-se para isto, pistilo e almofariz. Posteriormente, o macerado foi filtrado em gaze dupla e realizada a contagem dos esporos em câmara de Newbauer e ajustada a concentração para $10^{6}$ conídios $/ \mathrm{mL}$.

\section{Ação dos produtos sobre o crescimento micelial de Lasiodiplodia theobromae}

Discos com cinco milímetro de diâmetro contendo estruturas fúngicas proveniente de cultura de sete dias de L. theobromae foram repicados para o centro de placas de Petri com $90 \mathrm{~mm}$ de diâmetro, contendo meio de cultura de BDA, previamente autoclavado, e acrescido de cada dosagem dos respectivos produtos. Para os tratamentos com LUV, as placas contendo meio de cultura foram expostas à radiação nos tempos de $10 \mathrm{~min}$., $20 \mathrm{~min}$. e $30 \mathrm{~min}$. onde, após cada tempo foi depositado um disco de meio contendo estruturas do fitopatógeno. A testemunha constou de discos de meio de cultura contendo estruturas do fitopatógeno em meio BDA, sem qualquer produto. As placas foram mantidas na temperatura de $28 \pm 2{ }^{\circ} \mathrm{C}$ e $84 \%$ de umidade relativa. Após 48 horas avaliou-se o crescimento micelial com o auxílio de uma régua milimetrada, medindo-se o diâmetro, em dois sentidos opostos. O delineamento estatístico foi inteiramente casualizado, com seis repetições, constituindo 22 tratamentos. As médias foram analisadas no SISVAR sendo submetidas ao teste de Scott Knott a $5 \%$ de probabilidade.

\section{Ação dos produtos sobre a podridão peduncular em manga}

Depois de submetidas aos tratamentos, citados anteriormente, as frutas foram colocadas em bandejas plásticas contendo papel toalha. A inoculação com o fitopatógeno foi realizada em três diferentes tempos 
para cada dosagem: imediatamente (T1), 12 horas (T2) e 24 horas após os tratamentos (T3).

As frutas foram inoculadas fazendo-se ferimentos com auxilio de um perfurador (cinco pontas, abrangendo $5 \mathrm{~mm}$ de diâmetro e $2 \mathrm{~mm}$ de profundidade) flambado e, sobre cada ferimento, depositou-se $10 \mu \mathrm{L}$ do inóculo. Após cada tempo de inoculação foram promovidas câmaras úmidas, em cada bandeja contendo as frutas, as quais foram mantidas em temperatura e umidade relativa, controladas para $28 \pm 2{ }^{\circ} \mathrm{C}$ e $84 \%$, respectivamente. Após 48 horas de cada tempo da inoculação, retiraramse as câmaras úmidas e as frutas permaneceram nas mesmas condições de temperatura e umidade relativa. As avaliações foram realizadas diariamente após a retirada da câmara úmida, até o quarto dia, medindose o diâmetro da lesão (DL), expresso em mm, utilizando-se um paquímetro.

\section{Delineamento experimental e análises estatísticas}

$\mathrm{O}$ experimento foi montado em parcelas subdivididas no tempo T1, T2 e T3. O delineamento estatístico utilizado foi inteiramente casualizado com 24 tratamentos e oito repetições. Os resultados referentes aos índices médios de severidade foram transformados em representações gráficas do progresso da doença durante o período de avaliação pela utilização dos dados originais de incidência da doença, calculada a área abaixo da curva de progresso da doença (AACPD) pela expressão: AACPD $=\{\mathrm{S}[(\mathrm{yi}+\mathrm{yi}+1) / 2] .(\mathrm{ti}+1-\mathrm{ti})\}$, onde yi $\mathrm{e}$ yi+1 são os valores de incidência observados em duas avaliações consecutivas e ti+1 - ti o intervalo entre avaliações (9). Os valores de
AACPD foram submetidos à análise de variância. As variáveis significativas no Teste F foram submetidas ao Teste de Skott Knott a $5 \%$ de probabilidade.

\section{RESULTADOS E DISCUSSÃO}

Efeito dos tratamentos na incidência e na área abaixo da curva de progresso da doença (AACPD) da podridão peduncular em manga

Os resultados revelaram que os tratamentos utilizados foram eficazes na redução da doença, constatando-se AACPD significativamente menor em relação à testemunha. Quando avaliados para tempos de inoculação, verificou-se maior eficiência dos tratamentos até 12 horas. Para o T3 não houve diferença significativa entre os tratamentos e entre estes e a testemunha (Tabela 1). No T1, os melhores tratamentos foram FP (D1) e CC (D2). Quando avaliados in vitro, estes tratamentos não reduziram, significativamente, o crescimento micelial do fitopatógeno, o que permite sugerir uma ação protetora desses tratamentos sobre frutas. Este efeito foi verificado até 12 horas após os tratamentos. Os outros tratamentos não foram estatisticamente diferentes dos anteriores, exceto CC (D1), EA, EM e FP (D2), CC e ECM (D3). No T2 os melhores tratamentos foram CC, AH e EA (D1) e FP (D2). Enquanto EA, EM e LUV (D3); EM, EA, LUV e AH (D2), EM e ECM (D1) não diferiram estatisticamente da testemunha.

Tabela 1: Valores $(\mathrm{mm})$ da área abaixo da curva de progresso da severidade da podridão peduncular em manga causada por Lasiodiplodia theobromae

\begin{tabular}{|c|c|c|c|}
\hline \multirow[t]{2}{*}{ Tratamento } & \multicolumn{3}{|c|}{ Tempo de inoculação após tratamento } \\
\hline & Imediato & 12 horas & 24 horas \\
\hline Acido Hidroxibenzóico 1 & $15,25 \mathrm{Aa}^{*}$ & $6,80 \mathrm{Aa}$ & $156,54 \mathrm{Ba}$ \\
\hline Acido Hidroxibenzóico 3 & $15,43 \mathrm{Aa}$ & $29,91 \mathrm{Ab}$ & $114,45 \mathrm{Ba}$ \\
\hline Cloreto de cálcio 1 & $63,75 \mathrm{Bb}$ & $00,00 \mathrm{Aa}$ & $110,31 \mathrm{Ca}$ \\
\hline Cloreto de cálcio 3 & $51,43 \mathrm{Ab}$ & $19,43 \mathrm{Ab}$ & $106,67 \mathrm{Ba}$ \\
\hline Extrato de alho 1 & $2,73 \mathrm{Aa}$ & $11,11 \mathrm{Aa}$ & $114,50 \mathrm{Ba}$ \\
\hline Extrato de alho 2 & $55,87 \mathrm{Ab}$ & $85,72 \mathrm{Bc}$ & $105,68 \mathrm{Ba}$ \\
\hline Extrato de alho 3 & $15,56 \mathrm{Aa}$ & $37,46 \mathrm{Ac}$ & $106,31 \mathrm{Ba}$ \\
\hline Extrato casca de manga 1 & $36,93 \mathrm{Ab}$ & $55,58 \mathrm{Bc}$ & $132,97 \mathrm{Ca}$ \\
\hline Extrato de melão 2 & $55,86 \mathrm{Ab}$ & $39,26 \mathrm{Ac}$ & $118,40 \mathrm{Ba}$ \\
\hline Extrato de melão 3 & $17,81 \mathrm{Aa}$ & $75,73 \mathrm{Bc}$ & $107,81 \mathrm{Ca}$ \\
\hline Fosfato de potássio 1 & $2,18 \mathrm{Aa}$ & $31,92 \mathrm{Bb}$ & $110,33 \mathrm{Ba}$ \\
\hline Fosfato de potássio 2 & $67,12 \mathrm{Bb}$ & $15,02 \mathrm{Aa}$ & $102,16 \mathrm{Ca}$ \\
\hline Fosfato de potássio 3 & $16,07 \mathrm{Aa}$ & $34,62 \mathrm{Ab}$ & $105,37 \mathrm{Ba}$ \\
\hline Luz UV 1 & $22,91 \mathrm{Aa}$ & $46,71 \mathrm{Ac}$ & $111,41 \mathrm{Ba}$ \\
\hline Luz UV 2 & $19,62 \mathrm{Aa}$ & $76,00 \mathrm{Bc}$ & $82,25 \mathrm{Ba}$ \\
\hline Luz UV 3 & $21,35 \mathrm{Aa}$ & $55,08 \mathrm{Bc}$ & $90,16 \mathrm{Ba}$ \\
\hline Testemunha & $112,12 \mathrm{Ac}$ & $91,17 \mathrm{Ac}$ & $132,66 \mathrm{Aa}$ \\
\hline
\end{tabular}

CV (tratamento) $=31,29$

CV $($ tempo de inoculação $)=\mathbf{4 4 , 1 9}$

*Letras maiúsculas na horizontal e minúscula na vertical, não diferem entre si pelo teste de Skott Knott a $5 \%$ de probabilidade. 
Pesquisas têm demonstrado a eficiência do cálcio para o controle de fitopatógenos. Souza et al. (26) verificaram que CC reduziu a área lesada pela podridão parda causada por Monilinia fructicola (Winter) Honey em $34,33 \%$, e o índice de doença de pêssegos em $29 \%$, quando comparados às frutas tratadas com água. Freire Junior e Chitarra (13) avaliaram o efeito de cloreto de cálcio sobre a antracnose em mangas e verificaram que existe uma correlação positiva entre o CC aplicado e a quantidade deste elemento na casca, porém com pouca penetração para a polpa da fruta, o que demonstra que esse elemento age positivamente na diminuição dos sintomas da doença. Em pós-colheita de frutas é, usualmente, utilizado para retardar o amadurecimento e, consequientemente, aumentar a vida de prateleira das frutas (1).

Assim como o cálcio, o potássio é eficiente também para retardar o amadurecimento fisiológico em frutas colhidas. Embora pesquisas demonstrem que fontes de FP sejam eficientes para estimular a esporulação de fungos (23), os resultados obtidos evidenciam a ação desse produto para o controle da podridão por L. theobromae em manga. Os resultados observados neste trabalho foram semelhantes aos descritos por Brackmann et al. (8), os quais verificaram que a aplicação em pós-colheita, em maçãs 'Fuji', tratadas com fosfito de potássio $\left(250 \mathrm{~mL} 100 \mathrm{~L}^{-1}\right)+\mathrm{CaCl} 2(2 \%)$, proporcionou menor incidência de podridões e menor diâmetro de lesão.

Verificando a eficácia dos extratos vegetais, ressalta-se que, nas dosagens testadas neste experimento não houve fitotoxidez de qualquer dos extratos sobre as frutas. Apesar de alguns tratamentos com extratos de plantas terem demonstrado ação antifúngica, notou-se ação protetora desse quando a inoculação com o fitopatógeno ocorreu 12 horas após os tratamentos. Esses resultados estão coniventes com aqueles descritos por Celoto et al. (10), os quais verificaram a eficiência do extrato de melão-de-são-caetano, metanólico e aquoso, inibiu em $80 \%$ e $70 \%$, respectivamente, o desenvolvimento de lesões de antracnose em bananas, quando aplicados até dois dias antes da inoculação do fungo. Junqueira et al. (17) verificaram um eficiente controle da antracnose em mangas utilizando extrato bruto de sucupira. $\mathrm{O}$ controle da podridão peduncular foi constatado nesta pesquisa, por ECM quando se verificou resultado satisfatório na redução da AACPSD na dosagem um (T1) bem como nas dosagens 2 e 3 (T2). Estes resultados não puderam ser comparados com outros, por ser esta, a primeira pesquisa a empregar o extrato de casca de manga em pesquisa com fitopatógeno. Entretanto, estudos histoquímicos realizados nesse extrato revelaram a existência de compostos fenólicos (7), os quais podem ter efeito fungitóxico contra $L$. theobromae, como foi verificado no experimento in vitro, ou ter induzido respostas de defesa nas frutas, já que a proteção foi estendida até 12 horas. Entre estes compostos houve maior expressão da mangiferina, uma xantona que possui, entre outras, atividade antioxidante e protetora em manga. Ainda com relação a este assunto, Prusky e Keen (24) constataram a existência do resorcinol, composto antifungico presente na casca de manga cv. Tommy Atkins.

O AH também foi eficiente no controle da doença. Os resultados obtidos nesta pesquisa são compatíveis com aqueles observados por Zainure et al. (30). Estes pesquisadores constataram que o tratamento pós-colheita com ácido salicílico foi eficaz na supressão da antracnose em mangas. Poucas pesquisas envolvendo fitopatógenos têm utilizado o AH, principalmente com frutas na pós-colheita. Entretanto, análogos do acido salicílico têm sido bastante estudados para o controle de doenças de plantas (20).

Luz ultravioleta não foi eficiente no controle da doença quando as frutas foram expostas por 30 minutos. Embora não tenha sido constatado nenhum dano visível na casca das frutas submetidas a este tempo de exposição, pode ter ocorrido efeito contrário, debilitando os tecidos das frutas e favorecendo o ataque do fitopatógeno. Em contra partida ficou demonstrado o efeito positivo deste tratamento em outros patossistemas $(3,27,29)$. Bassetto (4) constatou que a UV-C foi eficiente no controle curativo de Rhizopus stolonifer (Ehrenb.) Vuill. e o tempo de exposição de $10 \mathrm{~min}$. foi o que apresentou melhor resultado. Entretanto, Cia (12) constatou ineficiência da radiação UV-C no controle de podridões pós-colheita em mamões cv. Golden inoculados com Colletotrichum gloeosporioides (Pen) Sac., e tratados com UV-C de 0 a 2,4 kJ.m-2 após 10 horas da inoculação, embora estas mesmas doses tenham revelado efeito germicida in vitro para este fitopatógeno. Em contra partida, Gonzalez Aguiar et al. (14) utilizaram este tratamento para manter a qualidade pós-colheita em mangas cv. Tommy Atkins, tratadas por 10 minutos, e concluíram que a radiação UV-C pode ser utilizada como um método rápido e eficaz para preservar a vida pós-colheita de manga madura sem afetar negativamente a qualidade de determinados atributos, bem como, aumentar o tempo de prateleira.

Diante dos resultados observados nesta pesquisa, pode-se inferir que métodos físicos e biológicos se constituem em alternativas viáveis e desejáveis em relação ao químico tradicional, para o controle da podridão peduncular em mangas na fase pós-colheita em função de não deixarem resíduos tóxicos nas frutas tratadas.

Efeito dos tratamentos sobre o crescimento micelial de Lasiodiplodia theobromae

Constatou-se interação significativa entre os tratamentos e dosagens (Figura 1).

Os tratamentos influenciaram no crescimento de L. theobromae, in vitro. $\mathrm{O}$ melhor tratamento foi com FP (D3). No experimento in vivo observaram-se resultados relevantes no controle da AACPSD por fosfato de potássio, principalmente quando as frutas foram tratadas e imediatamente inoculadas, ratificando a ação fungitóxica do produto sobre $L$. theobromae. Na dosagem D2, o efeito fungitóxico ainda foi verificado, embora no experimento in vivo, este tratamento tenha sido eficiente para ativar respostas de defesa na fruta. Geralmente produtos indutores de resistência não atuam sobre o fitopatógeno. Os extratos brutos das plantas testadas também revelaram resultados significativos no controle do crescimento micelial de $L$. theobromae, ressaltando-se os tratamentos EA (D2) e ECM (D2 e D3). Entretanto, quando avaliada a ação desses tratamentos in vivo, apenas o ECM (D2) foi significativamente eficiente na redução da severidade da doença, quando a inoculação foi realizada imediatamente e 12 horas após os tratamentos. Neste intervalo, a dosagem D3 também revelou reduções significativas, sugerindo a eficiência desses tratamentos para proteção das frutas. Os tratamentos com extrato de melão-de-são-caetano tiveram ação fungitóxica intermediárias em relação aos demais, mas, quando comparados à testemunha constatou-se menor diâmetro de colônia, embora na dosagem D3 tenha sido eficiente na redução da doença, quando a inoculação ocorreu imediatamente. Esse resultado sugere que o referido tratamento, provavelmente, induziu alguma resposta de defesa nas frutas. Extratos de plantas têm demonstrado efeito relevante no controle de fitopatógenos, tanto por sua ação fungitóxica direta quanto por alterações fisiológicas na planta, como indução de enzimas relacionadas à patogênese e fitoalexinas, lignificação da folha, entre outras (25). Estes autores também relataram que as pesquisas in vitro realizadas até o momento indicam o potencial de plantas medicinais no controle de fitopatógenos.

O AH (D1), CC (D1;D2) e LUV (D1;D2;D3) não revelaram eficiência contra o fitopatógeno no teste in vitro. Entretanto, quando testados nas frutas que foram submetidas às inoculações imediatas, 


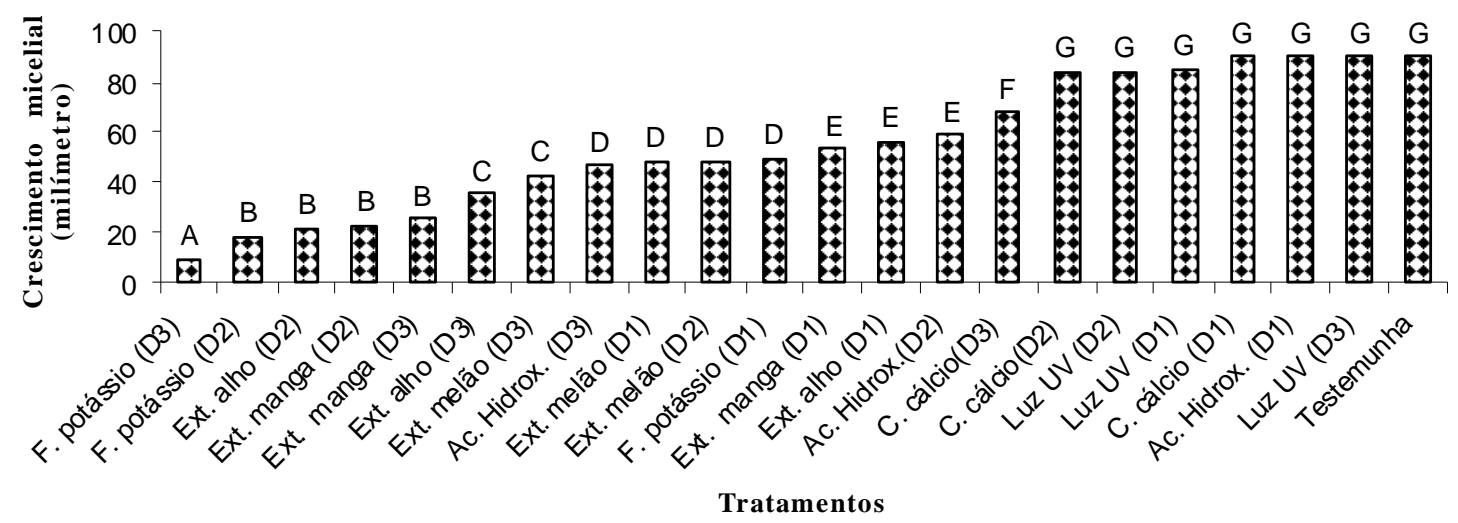

Figura 1: Ação dos produtos e suas respectivas dosagens sobre o crescimento micelial de Lasiodiplodia theobromae, in vitro. Tratamentos com mesma letra não difere entre si, pelo teste de Scott-knott a $5 \%$ de probabilidade. D1= dosagem um; D2= dosagem dois; D3= dosagem três. F.= fosfato, Ext.= extrato, Ac. $=$ ácido, C. $=$ cloreto, Hidrox = hidroxidobenzóico.

estes, com exceção do CC (D1), ficaram entre os melhores tratamentos (Tabela 1). Quando a ação desses foi testada após 12 horas o efeito protetor foi ainda melhor para CC (D1) e AH (D1), seguidos por CC (D3) e AH (D3). Dessa forma pode-se concluir que estes tratamentos agem ativando respostas de defesa na fruta. Para o $\mathrm{AH}$ ainda não existem referências que evidenciem seu efeito in vitro sobre qualquer fitopatógeno. Entretanto, Cia (12) verificou que o ácido salicílico inibiu o crescimento micelial e a germinação de $C$. gloeosporioides, in vitro.

Os tratamentos com LUV não foram eficientes para proteção das frutas até 12 horas. Cia (2005) observou que embora a UV-C tenha apresentado efeito germicida in vitro sobre C. gloeosporioides, em doses acima de 0,2 kJ.m-2 não foi eficiente em suprimir a infecção nos frutos inoculados antes da radiação. Bassetto et al. (3) testaram radiações de LUV sobre o crescimento micelial de $M$. fructicola e $R$. stolonifer, constataram que apenas as doses aplicadas durante um e 10 min. de exposição reduziram o crescimento micelial de $M$. fructicola, enquanto que a aplicação da luz UV-C entre 10-15 minutos reduziu o crescimento micelial de $R$. stolonifer e a dose aplicada durante 30 minutos inibiu completamente o crescimento micelial deste fungo. Entretanto, esta metodologia difere da empregada neste estudo, onde as estruturas do fitopatógeno não foram diretamente expostas à radiação.

\section{AGRADECIMENTOS}

Os autores agradecem ao Conselho Nacional de Desenvolvimento Tecnológico e Científico, CNPq pela concessão de bolsa de estudo ao primeiro autor e pelo financiamento parcial dos experimentos; ao doutorando Eudes Arruda de Carvalho e a Dr ${ }^{\mathrm{a}}$ Luciana Maria de Lima, pelo auxílio nas análises dos dados.

\section{REFERÊNCIAS BIBLIOGRÁFICAS}

1. Aguayo, E.; Victor, H.; Artés, EF. Effect of hot water treatment and various calcium salts on quality of fresh-cut 'Amarillo'melon, Postharvest Biology and Technolology, Amsterdan, n. 47, p.397406, 2008

2. Barkai-Golan, R. Postharvest diseases of fruits and vegetables: development and control. Amsterdan, Elsevier, 2001. 418p.

3. Bassetto, E.; Amorim, L.; Benato, E.A.; Gonçalves, F.P.; Lourenço, S.A. Efeito da irradiação UV-C no controle da podridão parda
(Monilinia fructicola) e da podridão mole (Rhizopus stolonifer) em pós-colheita de pêssegos. Fitopatologia Brasileira, Lavras, v.32, n.5, p. 393-399, 2007.

4. Basseto, E. Quantificação de danos ao longo da cadeia produtiva de pêssegos e avaliação de métodos alternativos de controle de doenças pós-colheita. 2006. 125 f. Tese (Doutorado em Agronomia). Escola Superior de Agricultura "Luiz de Queiroz, Piracicaba.

5. Brandão, M.C.C.; Maia, G.A.; Lima, D.P.; Parente, E.J.S.; Campello, C.C.; Nassui, R.T.; Feitosa, T.; Sousa, P.E.M. Análise físico química, microbiológica e sensorial de frutos de manga submetidos à desidratação osmótico solar. Revista Brasileira de Fruticultura, Cruz das Almas, v.25, n.1, p.38-41, 2003.

6. Benato, E.A.; Sigris, J.M.M.; Hanashiro, M.M.; Magalhães, M.J.M.; Binotti, C.S. Avaliação de fungicidas e produtos alternativos no controle de podridões pós-colheita em maracujá-amarelo. Summa Phytopathologica, Botucatu, v.28, p.299-304, 2002.

7. Berardini, N.; Fezer, R. Conrad, J.; Beifuss, U.; Carle, R.; Schieber, A. Screening of mango (Mangifera indica L.) cultivars for their contents of flavonol O- and xanthone C-glycosides, anthocyanins and pectin. Journal of Agricultural and Food Chemistry, Easton, v. 53, p.1563-1570, 2005.

8. Brackmann, A.; Giehl, R.F.H.; Ivan S. I.; Steffens, C.A. Fosfitos para o controle de podridões pós-colheita em maçãs 'Fuji' durante o armazenamento refrigerado. Ciência Rural, Santa Maria, v.34, p.1039-1042, 2004.

9. Campbell, C. L.; Madden, L. V. Introduction to plant disease epidemiology. New York: John Willey \& Sons, 1990. 532p.

10. Celoto, M.I.B.; Papa, M.F.S.; Sacramento, L.V.S.; Juari C. F. Atividade antifúngica de extratos de plantas a Colletotrichum gloeosporioides. Acta Science Agronomic, Maringá, v.30, n.1, p.1-5, 2008.

11. Cia, P.; Paschoalati, S.F.; Benato, E.A. indução de resistência no manejo de doenças pós-colheita. In: Reunião Brasileira de Indução de Resistência de Plantas a Patógenos. Universidade Federal de Lavras. Lavras, 2007. p. 245-269.

12. Cia, P. Avaliação de agentes bióticos e abióticos na indução de resistência e no controle póscolheita da antracnose (Colletotrichum gloeosporioides) em mamão (Carica papaya). 2005.197 p. Tese (Doutorado em Fitopatologia) - Escola Superior de Agricultura "Luiz de Queiroz", Universidade de São Paulo, Piracicaba, 2005.

13. Freire júnior, M.; Chitarra, A.B. Efeito da aplicação do cloreto de cálcio nos frutos da manga 'Tommy Atkins' tratados hidrotermicamente. Pesquisa Agropecuária Brasileira, Rio de Janeiro, v.34, n.5, p.761-769, 1999 .

14. Gonzalez-Aguilar, G.A.; Wang, C.Y.; Buta, J.G.; Krizek, D.T. Use of UV-C irradiation to prevent decay and maintain postharvest 
quality of ripe 'Tommy Atkins' mangoes. International Journal of Food Science and Technology, Oxford, n.36, p.767-773, 2001.

15. Gonzalez, E.; Umana, G.; Arauz, L.F. Combate de la pudricion peduncular del mango causada por Botryodiplodia theobromae Pat. mediante el mantenimiento de los pedicelos y el deslechado sobre laminas. Agronomia Costarricense, Costa Rica, v. 23, n.1, p. 31-35, 1999 .

16. IBRAF-Instituto Brasileiro de Frutas. Estatísticas. Disponível em: h t t p://www.ibraf.org.br/estatisticas/Exportação/ Comparativo_das_Exportações_Brasileiras_de_Frutas_frescas_Jan_Out_2008.pdf. Acesso em: 02 mar. 2009.

17. Junqueira, N.T.V.; Nascimento, A.C.; Ramos, V.H.V.; Lage, D.A.C.; Crahl, L.L.; Almeida, D.A.; Cabral, G.A. Efeito de produtos biológicos e químicos no controle da antracnose e na conservação da manga cv. Palmer em pós-colheita. Boletim de Pesquisa e Desenvolvimento, Embrapa Cerrados, nov., 2003.

18. Kader, A. (ed.) Postharvest Technology of Horticultural Crops. 3ed. Riverside: UC Regents, 2002. 535p.

19. Lins, S.R.O., Alves, E., Oliveira, S.M.A. Ultrastructural analysis of on twigs and petioles of mangos, with and without symptoms of rot petioler, Belo Horizonte, Sociedade Brasileira de microscopia e Microanálise. 2009. CD-ROOM.

20. Nascimento, A.R.; Fernandes, P.M.; Rocha, M.R.; Silva, E.A. Fontes de fosfito e acibenzolar-s-metil no controle de doenças e produtividade do tomateiro. Bioscience Jounal, Uberlândia, v.24, n.1, p.53-59, 2008.

21. Nurnberger, T.; Brunner, F. Innate immunity in plants and animals: emerging parallels between the recognition of general eliciadores and pathogen-associated molecules. Current Opinion in Plant Biology, Cambridge, v.5, n.4, p.318-324, 2002.

22. Palazón, I.; Palazón, C.F. Micosis de los productos cosechados. In: Llácer, G.; López, M.M.; Trapero, A.; Bello, A. (Ed.) Patología vegetal. 2. ed. Phytoma-España, Valencia, n.2, p.967-994, 2000.
23. Penariol, M.C.; Monteiro, A.C.; Pitellii, R.A. Crescimento e esporulação de Bipolaris euphorbiae cultivado sob diferentes condições nutricionais. Ciência Rural, Santa Maria, v.38, n.7, 2008.

24. Prusky, D.; Keen, N. T. Involvement of preformed antifungal compounds in the resistance of subtropical fruits to fungal decay. Plant Disease, Saint Paul, v.77, p.114-119, 1993.

25. Schwan-Estrada, K.R.F.; Stangarlin, JR. Extratos e óleos essenciais de plantas medicinais na indução de resistência. In: Cavalcanti, L.S, Di Piero, R.M.; Cia, P.; Pascholati, S.F.; Resende M.L.V.; Romeiro, R.S. (Eds.) Indução de resistência em plantas a patógenos e insetos. Piracicaba. Fealq, 2005. p.125-132.

26. Souza, A.L.B.; Chitarra, M.I.F.; Chitarra, A.B.; Machado, J.C. Resistência pós-colheita do pêssego (Prunus persica cv. biuti) a Monilinia fructicola: indução de respostas bioquímicas pela aplicação do cacl2 no local da injúria. Ciências e Agrotecnologia, Lavras, v.23, n.4, p.864-874, 1999.

27. Stevens, C.; Liu, J.; Khan, V.A.; Lu, J.Y.; Kabwe, M.K.; Wilson, C.L.; Igwegbe, E.C.K.; Chalutz, E.; Droby, S. The effects of lowdose ultraviolet light-C treatment on polygalacturonase activity, delay ripening and Rhizopus soft rot development of tomatoes. Crop Protection, Guildford, v. 23, p.551-554, 2004.

28. Terry, L.A.; Joyce, D.C. Elicitors of induced disease resistance in posharvest horticultural crops: a brief review. Postharvest Biology and Technoly, Amsterdam, v.32, p.1-13, 2004.

29. Wilson, C.L.; El Ghaouth, A.; Chalutz, E.; Croby, S.; Stevens, C.; Lu, J.Y.; Khan, V.; Arul, J. Potential of induced resistance to control postharvest diseases of fruits and vegetables. Plant Disease, Saint Paul, v.78, p.837-844, 1994.

30. Zainuri, A.; Joyce, D.C.; Wearing, A.H.; Coates, L.; Terry, L. Effects of phosphonate and salicylic acid treatments on anthracnose disease development and ripening of 'Kensington Pride' mango fruit. Australian Journal Express Agriculture, Melbourne, n. 41, p. $805-813.2001$ 